\title{
THE ISOLATION OF VINCANINE AND VINCANIDINE
}

\section{FROM THF ROOTS OF Vinca erecta}

U. Osmanov, Kh. N. Aripov,

UDC 547.944/945

and T. T. Shakirov

The roots of the plant $V$. e recta growing in Central Asia form the raw material for the isolation of vincanine [1] and vincanidine [2].

When vincanine is produced by a published method [3], the vincanidine remains almost completely on the cation-exchange resin, and its desorption requires the consumption of a la rge amount of solvent and time.

We have developed a method for isolating these alkaloids from the roots of $\mathrm{V}$. e recta in which it is possible to obtain vincanidine in good yield and to increase the yield of vincanine by $\overline{10 \%}$ as compared with the existing method.

The comminuted roots collected in 1972 in the Osh oblast $(5 \mathrm{~kg}$ ) were charged into five extractors and extracted with $1 \% \mathrm{H}_{2} \mathrm{SO}_{4}$ by the battery extraction method at the rate of 226 liters $/ \mathrm{h} \cdot \mathrm{m}^{2}$ (consumption 4 liters $/ \mathrm{h}$ ). Each 10 liters of extract was made alkaline with conc. $\mathrm{NH}_{4} \mathrm{OH}$ to $\mathrm{pH} 8-8.5$, and the alkaloids were extracted with chloroform. The aqueous extract was checked for the absence of alkaloids by thinlayer chromatography on silica gel [4]. A total of 50 liters of extract was obtained which was treated with 30 liters of chloroform.

The combined chloroform extracts were evaporated to 5 liters, and the phenolic alkaloids were extracted with $5 \% \mathrm{NaOH}$.

The alkaline solution was made acid with $10 \% \mathrm{H}_{2} \mathrm{SO}_{4}$, washed once with ether, and was made alkaline again with $\mathrm{NH}_{4} \mathrm{OH}$ to $\mathrm{pH} \mathrm{8-8.5}$ and the phenolic alkaloids were extracted with 20 liters of ether. When the ether was concentrated, crystals of vincanidine precipitated $-17.5 \mathrm{~g}$, or $70 \%$ of the amount in the raw material.

The nonphenolic alkaloids from the chloroform were transferred into $10 \% \mathrm{H}_{2} \mathrm{SO}_{4}$, and this solution was made alkaline to pH 8-8.5 and extracted with 10 liters of benzene. Evaporation of the benzene solution gave $25.5 \mathrm{~g}$ of vincanine, or $85 \%$ of the amount in the raw material.

\section{LITERAT URE CITED}

1. P. Kh. Yuldashev and S. Yu. Yunusov, Dokl. Akad. Nauk UzSSR, 12, 24 (1952).

2. Kh. U. Ubaev, P. Kh. Yuldashev, and S. Yu. Yunusov, Izv. Akad. Nauk SSSR, II, 1992 (1965).

3. T. T. Shakirov and Kh. N. Aripov, Khim.-Farmats. Zh., No. 7, 56 (1967).

4. Sh. Z. Kasymov, Kh. N. Aripov, T. T. Shaki rov, and S. Yu. Yunusov, Khim. Prirodn. Soedin., 352 (1967).

Institute of the Chemistry of Plant Substances, Academy of Sciences of the Uzbek SSR. Translated from Khimiya Pri rodnykh Soedinenii, No. 3, pp. 442-443, May-June, 1973. Original article submitted December 29, 1972.

(c) 1975 Plenum Publishing Corporation, 227 West 17th Street, New York, N.Y. 10011. No part of this publication may be reproduced, stored in a retrieval system, or transmitted, in any form or by any means, electronic, mechanical, photocopying, microfilming, recording or otherwise, without written permission of the publisher. A copy of this article is available from the publisher for $\$ 15.00$. 